Revista Tecné, Episteme y Didaxis: TED. Año 2014, Número Extraordinario. ISSN Impreso: 0121-3814, ISSN web: 2323-0126 Memorias, Sexto Congreso Internacional sobre Formación de Profesores de Ciencias. 08 al 10 de octubre de 2014, Bogotá

\title{
La cuestión sociocientífica del Diagnóstico preimplantación genética (DPG) como posibilidad para una comprensión social de la ciencia por parte de futuros profesores
}

Moreno Sierra Diana Fabiola', Jandira Líria Biscalquini Talamoni², Washington Luiz Pacheco de Carvalho 3

Categoría 2. Trabajo de investigación

\section{Resumen}

El presente trabajo hace parte de una investigación más amplia y para efectos de este artículo se consideró la pregunta problema ¿Cuáles comprensiones sobre ciencia se van construyendo por parte de los licenciandos al abordar la polémica del Diagnóstico preimplantación genética (DPG)? Y como objetivo se planteó analizar dichas comprensiones en la perspectiva de la formación de profesores. El grupo participante correspondió a 14 estudiantes de licenciatura de una universidad colombiana que participaron de un seminario sobre la polémica del DPG, a través de lecturas de noticias de periódicos nacionales, presentaciones y debates. Algunos resultados indican comprensiones tales como la relación del desarrollo científico con aspectos éticos y la comprensión sobre la ciencia como factor de poder; las cuales posibilitan mayor entendimiento de la $\mathrm{NdC}$ con aspectos políticos y éticos necesarios para pensar la formación de profesores.

\section{Palabras clave}

Formación de profesores, Enseñanza de las Ciencias, Naturaleza de la ciencia (NdC).

\footnotetext{
1 Estudiante de Doctorado Educación en Ciencias, Unesp-Bauru. "Beca CAPES/CNPq-Brasil". diana.educi@gmail.com

2 Profesora Doctora del Departamento de Biología. UNESP/Bauru/SP/Brasil. talamoni@fc.unesp.br

3 Profesor Facultad de Ingeniería Unesp-llha Solteira-Brasil, washcar@dfa.feis.unesp.br
} 
Revista Tecné, Episteme y Didaxis: TED. Año 2014, Número Extraordinario. ISSN Impreso: 0121-3814, ISSN web: 2323-0126

Memorias, Sexto Congreso Internacional sobre Formación de Profesores de Ciencias. 08 al 10 de octubre de 2014, Bogotá

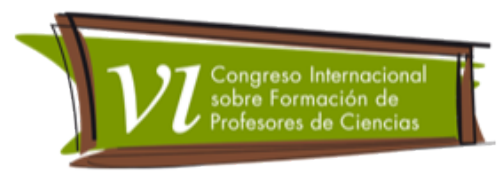

\section{Introducción}

Las controversias sociales sobre el uso de transgénicos, experimentación animal, clonación, uso de células madre, producción de medicamentos, entre otros asuntos, y particularmente la manipulación genética en humanos, constituyen CSC relevantes para la formación del profesorado, puesto que estos pueden llevar a nuevas comprensiones sobre la ciencia.

Según Gray e Bryce (2006) tanto la ciencia cuanto la educación en ciencias actualmente están más cargadas de valores y en ese sentido el profesor debe estar preparado para saber lidiar con cuestiones complexas y que conllevan puntos de vista diferentes, desarrollando habilidades reflexivas y conceptuales.

En este sentido, a pesar de que existen diversos trabajos en el área preocupados por la formación de profesores y la NdC (Lederman y Zeidler 2007; Auduriz-Bravo 2007), actualmente continúa siendo relevante la realización de propuestas que consideren el desarrollo del conocimiento científico y tecnológico actual, pues este se caracteriza por la incertidumbre, la polémica y los factores de riesgo. Aspectos que son de nuestro interés y que nos permite preguntarnos. A partir del abordaje de la CSC del DPG por parte de los estudiantes ¿ Cuáles comprensiones sobre ciencias se van construyendo a partir de esta polémica?

\section{Objetivo}

Analizar la comprensión de ciencia por parte de un grupo de estudiantes de licenciatura, a partir de la lectura de dos noticias sobre Diagnóstico preimplantación genética (DPG).

\section{Marco teórico}

Son características de las CSC: tener una base científica, ser un conocimiento de frontera, formar opiniones personales, ser presentadas por los medios de comunicación, envolver raciocinios éticos, análisis de costo-beneficio e implicaciones globales y locales (Ratcliffe y Grace, 2003). 
Revista Tecné, Episteme y Didaxis: TED. Año 2014, Número Extraordinario. ISSN Impreso: 0121-3814, ISSN web: 2323-0126

Memorias, Sexto Congreso Internacional sobre Formación de Profesores de Ciencias. 08 al 10 de octubre de 2014, Bogotá

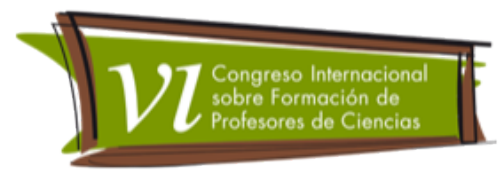

Diversos autores han reconocido el potencial de las CSC en los procesos educativos tales como: la promoción del desarrollo ético y moral en los estudiantes (Zeidler, 2003; Guimarães, 2011), la viabilidad en la comprensión de la NdC en la formación de profesores (Pedretti, 2003; Reis; Galvão, 2008), de la misma forma estas cuestiones contribuyen a potencializar la autonomía docente y el cuestionamiento de la ideología del currículo tradicional (Martínez, 2012).

El DPG es entendido como una técnica que consiste en hacer una biopsia al embrión, en el estado de ocho células para estudiar las enfermedades genéticas y de esta manera, seleccionar la célula que será implantada en el útero (Mejía, 2009). Esta técnica fue aplicada clínicamente en el año de 1990, y la primera experiencia fue divulgada en la revista Nature: "Pregnancies from biopsied human preimplantation embryos sexed by Y-specific DNA amplification" por el especialista Alan Handyside y sus colaboradores (1990). Originariamente esta técnica permitía detectar y evitar enfermedades genéticas como la anemia falciforme, la enfermedad de Tays-Sachs, la Talasemia entre otras, sin embargo, actualmente abarca otros usos como la selección de sexo por motivos no médicos o la selección de embriones inmunológicamente compatibles, etc.

Como se puede apreciar la complejidad de esta cuestión y a partir de las contribuciones de las investigaciones sobre formación de profesores, consideramos como referente teórico una visión crítica en la formación de profesores, a partir de los aspectos de la formación cultural de Theodor Adorno y la propuesta del profesor como intelectual de Henry Giroux.

\section{Metodología}

En este estudio se adoptó la investigación cualitativa, la cual hace énfasis en los procesos de interpretación de las realidades sociales (Baver, Gaskell, Allum, 2002). También utilizamos la teoría de análisis de contenido de acuerdo con Bardin (1977).

Los participantes de la investigación correspondieron a 14 estudiantes de licenciatura, 9 hombres y 5 mujeres, estudiantes de diferentes áreas, siendo 6 de Biología, 4 de Pedagogía Infantil, 2 de Ciencias Sociales y 2 de inglés. Las edades de estos estudiantes varían entre 17 y 29 años. La mayoría de estudiantes cursaban los últimos semestres. Los estudiantes participaron de la disciplina electiva "Formación de 
Revista Tecné, Episteme y Didaxis: TED. Año 2014, Número Extraordinario. ISSN Impreso: 0121-3814, ISSN web: 2323-0126

Memorias, Sexto Congreso Internacional sobre Formación de Profesores de Ciencias. 08 al 10 de octubre de 2014, Bogotá

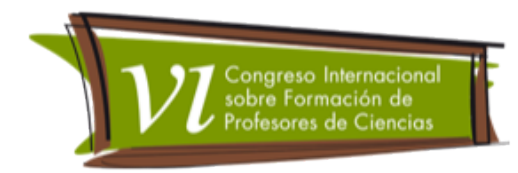

docentes en CSC", ofrecida en el año de 2013, en una universidad colombiana. Fueron realizados 25 encuentros de dos horas cada uno. La disciplina tenía como responsable dos profesores. Uno de ellos con formación en filosofía y la primera autora de esta investigación licenciada en Biología.

En los primeros encuentros se realizó una caracterización de las visiones de ciencia y en el quinto encuentro se incitó a los estudiantes a la discusión de cuestiones controvertidas en torno a la manipulación genética, el trabajo fue realizado a partir de la lectura de dos periódicos colombianos. Siendo las noticias de: Perilla, S. Avance colombiano en genética. El Tiempo. Colombia. 20 de febrero de 2004. Redacción vivir. La ciencia de nuevo se enfrenta a la ética: manipulación de embriones reabre una vieja polémica. El Espectador. Colombia. 9 de enero de 2009. Todos los encuentros fueron grabados en audio y contaron con el consentimiento de los participantes.

\section{Resultados}

A partir del trabajo realizado en grupo, las respectivas socializaciones y discusiones identificamos tres controversias:

1. El estatus del embrión.

2. El DPG como visión determinista.

3. Cuestión de acceso a la técnica.

La primera abarca nociones sobre la vida y lo vivo, considerando preocupaciones sobre la intervención humana hacia el embrión, de la misma forma aquí aparecen consideraciones de rechazo a la eliminación de embriones que presentan enfermedades. Aspectos bastantemente considerados por las estudiantes de Licenciatura en Pedagogía Infantil e inglés. Esta controversia también ha sido señalada por Habermas (2004, p.28) cuando pregunta ¿̇s compatible con la dignidad humana ser generado mediante reservas y solamente después de un examen genético ser considerado digno de una existencia y de un desarrollo?

La segunda controversia presentada especialmente por los estudiantes de la Licenciatura en Biología dice sobre la idea de perfección humana y de bienestar, en la cual no se reconocen las enfermedades como proceso natural. De la misma forma, hace parte la reflexión sobre la interacción genes y ambiente, y el cuestionamiento de 
Revista Tecné, Episteme y Didaxis: TED. Año 2014, Número Extraordinario. ISSN Impreso: 0121-3814, ISSN web: 2323-0126 Memorias, Sexto Congreso Internacional sobre Formación de Profesores de Ciencias. 08 al 10 de octubre de 2014, Bogotá

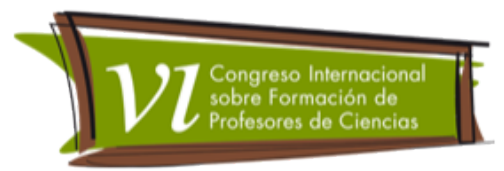

la selección natural versus el control del ser humano. Se trata de un genocentrismo, un peligro de genomania, genes y genomas no se accionan en el vacío, también el ambiente debe ser considerado en la biología humana (Leite, 2006).

La última cuestión apropiada por la mayoría del grupo encierra cuestiones de costo de esta técnica, implicando un acceso para pocos, sim embargo también una preocupación por procesos de masificación, consideraciones sobre Derechos Humanos e igualdad social, así como cuestiones de regulación. En ese sentido, se percibe elementos para pensar el desarrollo científico y tecnológico desde una lógica tecnocrática, la cual encierra una visión cientificista con aires democráticos, pero que realmente en este slogan se legitima la exclusión e ignorancia de la mayor parte de los ciudadanos (González, López y Luján 1996).

Además de las controversias presentadas, también fueron explícitos aspectos de falta de conocimiento, por ejemplo, comprensiones sobre el embrión y su desarrollo y visiones sobre el aborto. Sin embargo, para otros estudiantes además de estos vacíos, también estaba en juego sus creencias, lo que les dificultaba entender esta práctica. También se presentaron vacíos de conocimiento sobre la técnica usada, sintiendo curiosidad por sus implicaciones y el grado de efectividad.

A pesar de las controversias indicadas y de la falta de conocimiento, algunos estudiantes ya se mostraban de acuerdo con la eugenesia negativa, referente a enfermedades hereditarias, ya otros estudiantes consideraban la enfermedad como parte de un proceso natural, sólo un estudiante se mostró a favor de la eugenesia positiva, aquella que obedece a ciertas características deseables.

A partir de los resultados presentados, podemos resaltar dos aspectos importantes que al abordar la CSC del DPG llevaron a nuevas comprensiones sobre ciencia por parte de los estudiantes, estas necesariamente emergieron por la posibilidad del trabajo con una cuestión altamente polémica, de desarrollo actual y de abordaje interdisciplinar, diferente a un contenido tradicional, el cual es enseñado como verdadero y delimitado. Una primera comprensión se trata de la relación del desarrollo científico con aspectos éticos, lo cual es poco considerado por los estudiantes cuando piensan en ciencia, pues todavía existen visiones de neutralidad y bienestar del desarrollo científico y tecnológico, la otra comprensión considera la ciencia como factor de poder, pues está técnica puede generar diversos problemas, en especial de 
Revista Tecné, Episteme y Didaxis: TED. Año 2014, Número Extraordinario. ISSN Impreso: 0121-3814, ISSN web: 2323-0126 Memorias, Sexto Congreso Internacional sobre Formación de Profesores de Ciencias. 08 al 10 de octubre de 2014, Bogotá

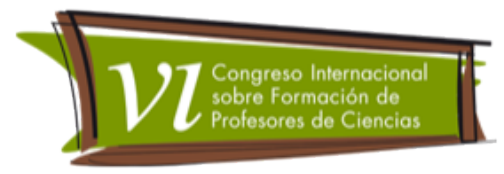

desigualdad entre los ciudadanos, además de llevar a una clasificación de personas, aquellas seleccionadas para no desarrollar enfermedades monogenéticas y las que tendrán ese tipo de enfermedades, en este mismo sentido problemas de discriminación con las actuales personas que sufren de alguna enfermedad grave.

\section{Conclusiones}

La primera comprensión sobre relación del desarrollo científico con aspectos éticos y la segunda comprensión sobre la ciencia como factor de poder expresadas por los estudiantes de licenciatura representan nuevos elementos para comprender la NdC más allá de los necesarios fundamentos epistemológicos, pero insuficientes para analizar la controversia del DPG y aquellas referidas a manipulación de la vida. Podemos percibir como el abordaje con CSC en la enseñanza demanda una formación crítica del profesor, en la cual la ciencia es entendida de manera más amplia del ámbito interno, ya que esta debe analizarse de acuerdo con aspectos políticos y éticos.

\section{Referencias Bibliográficas}

Adúriz-Bravo, Agustin. (2007) ¿¿ué naturaleza de la ciencia hemos de saber los profesores de ciencias?. Unesco. Disponible en:

http://bibliotecavirtual.educared.org/index.php/site/default/detalle/id/00000000013/qu e-naturaleza-de-la-ciencia-hemos-de-saber-los-profesores-de-ciencias Acceso: 22 de abril 2013

Bardin, Laurence.(1977). Análises de conteúdo. Lisboa: Edições 70.

Baver, Martin.; Gaskell, George.; Allum, Nicholas. (2002). Qualidade, quantidade e interesses do conhecimento: evitando confusões. In: Baver, M.; Gaskell, G. Pesquisa qualitativa com texto, imagem e som: um manual prático. Petrópolis, RJ: Vozes. 
Revista Tecné, Episteme y Didaxis: TED. Año 2014, Número Extraordinario. ISSN Impreso: 0121-3814, ISSN web: 2323-0126

Memorias, Sexto Congreso Internacional sobre Formación de Profesores de Ciencias. 08 al 10 de octubre de 2014, Bogotá

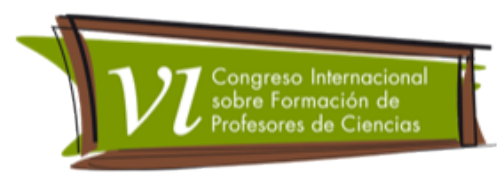

González, M; López, J.; Luján, J. (1996). Ciencia, Tecnología y Sociedad: Una introducción al estudio social de la ciencia y la tecnología. Madrid: Tecnos Gray, D. S.; Bryce, T. Socio-scientific issues in science education: implications for the professional development of teachers. Cambridge Journal of Education, Londres, 36, n. 2, Junho 2006. 171-192

Guimarães, Marcio. (2011) Raciocínio informal e a discussão de questões sociocientíficas: o exemplo das células-tronco humanas. Teses (Doutorado). Faculdade de Ciências da Universidade Estadual Paulista, Bauru

Habermas, Jürgem. (2004) O futuro da Natureza Humana: a caminho de uma eugenia liberalẹ Tradução Karina Jannini. São Paulo: Martins Fontes.

Handyside, A.; Kontogianni E.; Hardy, K.; Winston, R. (1990) Pregnancies from biopsied human preimplantation embryos sexed by $Y$-specific DNA amplification. Nature, $v$. 344 n. 6268, p.768-70.

Lederman, N.G. \& Zeidler, D.L. (2007). Science teachers/ conceptions of the nature of science: a review of research. Journal of Research in Science Teaching, 29, 331359.

Leite, Marcelo. Retórica determinista no genoma humano. Revista Scientiae studia. São Paulo. V.4 n.3 p.421-452. 2006

Martínez, Leonardo. (2012) Questões sociocientíficas na prática docente: ideologia, autonomia e formação de professores. São Paulo: Editora Unesp.

Mejía, Orlando. (2009). En el jardín de Mendel. Bioética, genética humana y sociedad. Medellín: editorial Universidad de Antioquia.

Ratcliffe, Mary \& Grace, Marcus. (2003). Science education for citizenship: teaching socio-scientific issues. Maidenhead: Open University Press.

REIS, Pedro.; GALVÃO, Cecília. Os professores de Ciências naturais e a discussão de controvérsias sociocientíficas: dois casos distintos. Revista electrónica de Enseñanza de la Ciencias. v. 7, n. 3, p. 746-772, 2008 
Revista Tecné, Episteme y Didaxis: TED. Año 2014, Número Extraordinario. ISSN Impreso: 0121-3814, ISSN web: 2323-0126

Memorias, Sexto Congreso Internacional sobre Formación de Profesores de Ciencias. 08 al 10 de octubre de 2014, Bogotá

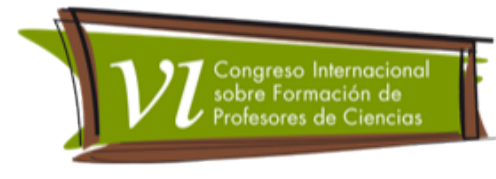

Pedretti, Erminia.(2003). Teaching science, technology, society and Environment (STSE) education: Preservice Teachers' philosophical and pedagogical landscapes, In: ZEIDLER, D. (Org). The role of moral reasoning on socioscientific issues and discourse in science education. The Netherlands: Kluwer Academic Publishers. 219239 